\title{
DIVIDENDOS E EFEITO CLIENTELA: EVIDÊNCIAS NO MERCADO BRASILEIRO
}

\author{
DIVIDENDS AND CLIENTELE EFFECT: EVIDENCE IN THE BRAZILIAN MARKET \\ DIVIDENDOS Y EFECTO CLIENTELA: EVIDENCIAS EN EL MERCADO BRASILEÑO
}

\section{RESUMO}

Investigou-se se características externas à operação da empresa, representativas de efeito clientela, diferenciam marginalmente a política de dividendos de firmas listadas na BM\&FBovespa, em uma amostra de 410 firmas (2.339 empresas/ano), no período de 1998 a 2010. Utilizaram-se regressão logística e regressão Tobit para os testes da hipótese, a qual propugna que existe associação estatisticamente significante entre a decisão de declarar dividendos - e seu montante - e o efeito clien-

tela, que não pôde ser rejeitada de maneira conclusiva. Pôde-se inferir que a política de dividendos de firmas brasileiras confirma, de modo parcial, a proposição de Miller e Modigliani (1961) acerca de o efeito clientela influenciar a decisão de dividendos das firmas; o impacto do efeito clientela, ademais, é devido a questões associadas a governança corporativa e a mecanismos de financiamento predominantes no mercado financeiro brasileiro.

PALAVRAS-CHAVE Dividendos, efeito clientela, estrutura de propriedade, sociedades brasileiras de capital aberto, regressão logística.

Allan Pinheiro Holanda allanpholanda@yahoo.com.br

Mestrando em Administração e Controladoria pelo Programa de Pós-Graduação em Administração e Controladoria, Universidade Federal do Ceará - Fortaleza - CE, Brasil

Antonio Carlos Dias Coelho accoelho@secrel.com.br

Professor da Faculdade de Economia Administração, Atuária, Contabilidade e Secretariado Executivo, Universidade Federal do Ceará - Fortaleza - CE, Brasil

\begin{abstract}
We investigated whether characteristics other than corporate operation, a proxy for clientele effect, marginally differentiated the dividend policies of 401 firms (2339 firm/years) traded on BM\&Fbovespa in the period 1998-2010. A statistically significant association between the decision to declare dividends (and amounts) and the clientele effect was hypothesized. Following testing with logistic and TOBIT regressions, the hypothesis could not be conclusively rejected. The dividend policies of Brazilian firms to some extent support Miller and Modigliani's (1961) proposition concerning the clientele effect and dividend decision. The impact of the latter is probably due to corporate governance issues and related to predominant mechanisms of financing in the Brazilian financial market.

keywords Dividends, clientele effect, ownership structure, brazilian public companies, logistic regression.

Resumen Se investigó si características externas a la operación de la empresa, representativas de efecto clientela, diferencian marginalmente la política de dividendos de empresas listadas en la BM\&FBovespa, en una muestra de 410 empresas (2.339 empresas/año), en el período de 1998 a 2010. Se utilizaron regresión logística y regresión Tobit para los tests de la hipótesis que propone que existe asociación estadísticamente significativa entre la decisión de declarar dividendos -y su monto- y el efecto clientela, que no puede ser rechazada de manera conclusiva. Se puede inferir que la política de dividendos de empresas brasileñas confirma, de modo parcial, la proposición de Miller y Modigliani (1961) acerca de que el efecto clientela influencia la decisión de dividendos de las empresas; el impacto del efecto clientela se debe, además, a cuestiones asociadas a gobierno corporativo y a mecanismos de financiación predominantes en el mercado financiero brasileño.

Palabras clave Dividendos, efecto clientela, estructura de propiedad, sociedades brasileñas de capital abierto, regresión logística.
\end{abstract}




\section{INTRODUÇÃO}

A política de dividendos envolve fundamentalmente a decisão de quanto do lucro será distribuído e de quanto será retido pela firma (LOSS e SARLO NETO, 2003). De acordo com Bueno (2000, p. 23) a decisão do que fazer com o lucro gerado pela firma em um período é "mais que uma simples questão de quanto distribuir (ou de quanto reter); trata-se de uma decisão sobre como serão financiados os futuros investimentos".

Já pela ótica do investidor, o dividendo é a parcela realizada da remuneração do capital que está investido na firma. Existem investidores que têm preferência por receber dividendos, enquanto outros preferem os ganhos de capital decorrentes da retenção; a teoria do efeito clientela preconiza que os investidores são direcionados a aplicar seus recursos em firmas com políticas de dividendos adequadas às suas preferências; tal escolha consideraria as características de seus fluxos de caixa pessoais ou corporativos.

A distribuição de dividendos para os acionistas, na opinião de Verdi (2001), é um assunto polêmico, pois não se sabe exatamente como as firmas e os investidores interpretam essa distribuição.

Diferentes teorias, como a da Relevância dos Dividendos (LINTNER, 1956; GORDON, 1959), a da Irrelevância dos Dividendos (MILLER e MODIGLIANI, 1961), a da Hipótese da Sinalização (ROSS, 1977), a da Hipótese do Agenciamento (JENSEN e MECKLING, 1976) e a do Efeito Clientela (MILLER e MODIGLIANI, 1961) foram propostas para explicar a política de dividendos, mas as evidências empíricas sobre uma teoria sempre invalidavam as evidências empíricas de teorias anteriores, o que, de acordo com Black (1996), criou o enigma dos dividendos, pois quanto mais se observam empiricamente as políticas de dividendos praticadas, mais se percebe que as decisões sobre dividendos se parecem com um enigma que contém partes que não se encaixam.

Desde que foi desenvolvida a teoria seminal sobre a política de dividendos por Modigliani e Miller, uma série de pesquisas foi realizada buscando esclarecer sobre fatores institucionais e econômicos, relacionados às firmas e aos acionistas, capazes de explicar como se decide o nível de distribuição de dividendos numa firma.

Pesquisas, adiante tratadas, apontaram fatores relacionados a esses agentes econômicos, como: oportunidade de crescimento; nível de investimento; setor de atividades; capacidade de geração e distribuição de lucros e características dos acionistas, que apresentaram significantes associações com políticas de dividendos, sem, contudo, explicá-las de maneira categórica.

Estudos anteriores, adiante detalhados, tentaram explicar a propensão em distribuir dividendos baseada nas expectativas dos acionistas em torno de suas preferências tributárias, o que implicaria, no Brasil, forçosamente optar por distribuir dividendos, já que no País sua tributação é nula, em detrimento de ganhos de capital, tributados quando de sua realização.

No caso do Brasil, portanto, a presença do efeito clientela, se houver, seria determinada por outros atributos institucionais, sejam características individuais dos acionistas, sejam especificidades da estrutura de propriedade das firmas ou, ainda, condicionantes do ambiente econômico nacional.

Em outras palavras, o efeito clientela impacta marginalmente a decisão das firmas brasileiras quanto às suas decisões de distribuição de dividendos? Ou seja, as firmas no Brasil consideram o tipo de acionistas para estipular sua decisão quanto à destinação de seus lucros anuais? Nesse caso, os acionistas reforçam e homologam tais políticas, preferindo investir em firmas que pratiquem determinada política de dividendos?

O objetivo da pesquisa gira em torno de examinar se características representativas da estrutura de propriedade e do tipo de acionistas diferenciam marginalmente firmas com diferentes e consistentes políticas de dividendos no ambiente societário brasileiro e derivam da necessidade de se esclarecer esse aspecto referente à disposição de as empresas brasileiras atenderem às expectativas de seus financiadores com capital próprio.

A pesquisa vem a propósito de recentes e continuadas tentativas de aproximar as empresas de seus financiadores, por meio de mecanismos de governança, pela emissão de leis e regulamentos de proteção aos minoritários e por implementação de sistemas de informações contábeis mais eficientes e transparentes (firmas de auditoria, níveis de listagem na BM\&FBovespa, adoção de práticas voluntárias de governança corporativa). Também fica implícito que tal cenário levaria a que a gestão da empresa passasse a ter mais preocupação mercadológica, de relação com investidores, levando as empresas a atentar para as características de seus financiadores no mercado acionário.

De outra parte, há que reconhecer a influência elevada do financiamento estatal às maiores empresas brasileiras, principalmente via BNDES e outros bancos oficiais, o que levaria as gestões das firmas assim financiadas a não atender a demandas mínimas de informação por investidores privados (COELHO, 2007). 
Ademais, a orientação jurídica brasileira de direito codificado força a que se declare política de dividendos estáveis, sob pena de as firmas obedecerem ao patamar mínimo de distribuição de dividendos (BRASIL, 1976), o que poderia tornar inócuos mecanismos de atração de capitais no mercado acionário; em outras palavras, a captação de novos recursos por emissão de ações pode ser diferenciada por política de dividendos que evidencie o efeito clientela, apesar da legislação restritiva.

Ampliamos as pesquisas sobre o assunto, investigando diretamente a associação entre diversos atributos do relacionamento firma/acionista; os estudos na realidade brasileira sobre o assunto focam, como se verá adiante, aspectos específicos do arranjo societário ou na influência da distribuição de dividendos no preço das ações; neste estudo, examina-se a capacidade marginal de se distinguir a política de dividendos em função da presença de elementos identificadores dos acionistas.

A investigação da relação entre as características representativas da estrutura de propriedade e dos acionistas investidores (minoritários) com a política de dividendos das companhias de capital aberto do Brasil, portanto, direciona a pesquisa.

A hipótese da pesquisa não pôde ser refutada, dado que atributos associados ao efeito clientela lograram significância estatística quanto a afetar marginalmente o nível de payout ou a decisão de declarar dividendos.

A pesquisa está estruturada em sete seções, incluindo esta introdução. Na seção seguinte, apresenta-se revisão de literatura abordando a temática da política de dividendos. Nas três seções seguintes, são abordados, respectivamente, o desenvolvimento da hipótese, o delineamento da pesquisa e os modelos e processamento. Na sexta seção, são apresentados os achados mais relevantes da investigação realizada. Por fim, as conclusões são apresentadas na última seção.

\section{SUPORTE TEÓRICO}

A política de dividendos tem sido tema de ampla investigação nas áreas econômica e financeira, já que nenhuma formulação teórica consegue sobressair às demais, estabelecendo previsibilidade de comportamento de firmas quanto à distribuição de lucros ou estabelecimento de preferência de acionistas que façam com que tal política impacte o valor da firma. Assim, não logram chegar a concordância quanto à influência da política de dividendos na avaliação da firma, como não conseguem estabelecer atributos que discriminem e prevejam políticas de dividendos.

De acordo com Procianoy e Verdi (2003, p. 2), "dentre as teorias que buscam explicar a política de distribuição de dividendos, pode-se dizer que ainda não houve consenso sobre a sua importância na valorização da firma", estabelecendo os autores que tais teorias dividem-se em quatro grupos quanto à sua influência na avaliação de firmas.

Conforme Procianoy e Verdi (2003), o primeiro grupo de teorias conjectura que maiores níveis de distribuição de lucros proporcionariam aumento dos preços das ações, dada a preferência pela liquidez dos agentes econômicos (hipótese da relevância dos dividendos); por consequência, essa postura também reduziria $\mathrm{O}$ fluxo de caixa disponível para os gestores, reduzindo expectativas de ineficiência na alocação de recursos (hipótese do agenciamento); o comportamento sugerido seria, ainda, uma forma de sinalizar a expectativa de lucros futuros (hipótese da sinalização).

De acordo com os mesmos autores, o segundo grupo de proposições acredita que a distribuição de lucros é irrelevante para os investidores (hipótese da irrelevância dos dividendos), uma vez que o importante é a maximização da geração de caixa pela empresa; assim, o lucro apenas seria distribuído no caso de a firma não conseguir alocação de recursos mais eficiente do que as que estariam disponíveis diretamente aos acionistas.

Já o terceiro grupo de teorias prevê que os investidores é que procurariam firmas com política de dividendos que atendam à sua própria expectativa quanto ao recebimento deles ou não (hipótese do efeito clientela).

Um quarto e último grupo de conjecturas coloca a política de dividendos como decisão sobre a destinação residual dos lucros após o autofinanciamento de investimentos decididos pela firma, os quais maximizariam a riqueza dos acionistas (hipótese do dividendo residual).

Destaca-se, para esta pesquisa, aquela que trata do possível Efeito Clientela, sobre a qual Miller e Modigliani (1961) dão relevo:

\footnotetext{
Se, por exemplo, a frequência de pagamentos utilizada pelas empresas corresponde exatamente à distribuição das preferências dos investidores, [...] cada corporação tenderia a atrair uma clientela satisfeita com suas taxas de distribuição de lucros. (MILLER e MODIGLIANI, 1961, p. 431, tradução nossa)
}

Esses autores argumentam que a política de dividendos de uma firma poderia formar uma clientela de 
investidores, ou seja, tal teoria está relacionada com o fato de que os investidores possuem preferências por firmas que atendam às suas expectativas em termos temporais de fluxo de caixa, associadas a seu fluxo de gastos, mantidas as demais condições constantes.

Graham e Kumar (2006) complementam o argumento base do Efeito Clientela, afirmando que as empresas que pagam maiores dividendos tendem a atrair investidores que dividendos, e isso leva ao equilíbrio entre política de dividendos e preferências de seus acionistas.

Ou seja, o Efeito Clientela deriva da hipótese de que existem investidores que evitam firmas que distribuam regularmente quantias na forma de dividendos, preferindo as que retenham seus lucros e que proporcionem ganhos de capitais. Por outro lado, outros investidores estariam interessados em receber fluxos de caixa imediatos e, assim, investirão em firmas que distribuam regularmente parte substancial dos seus lucros.

Quem primeiro tratou do Efeito Clientela associado à declaração de dividendos foram Elton e Gruber (1970), ao investigar o comportamento do preço das ações listadas na Bolsa de Nova Iorque no período de 1966 a 1967 com dividendo e ex-dividendo; segundo os autores, a variação de preços deveria ser igual ao valor recebido como dividendo, descontado o valor dos impostos. Os achados da pesquisa indicaram diferença no preço da ação antes e depois dos dividendos, concluindo os autores que as companhias pesquisadas buscavam atrair clientela que possuísse preferências quanto ao recebimento de dividendos condizente com sua política, evidenciando a presença do Efeito Clientela naquele momento e local, já que o ato de pagar dividendos foi precificado pelo mercado.

Outras pesquisas internacionais, apresentadas a seguir, acrescentaram evidências e enfoques ao assunto, também incluindo como explanadores do comportamento dos gestores na decisão de pagar ou não dividendos associações entre atributos de propriedade e o nível de distribuição de lucros.

La Porta e outros (2000) investigaram a relação entre a distribuição de lucros e a porcentagem de votos dos acionistas minoritários em empresas de 33 países. Os resultados da pesquisa indicaram relacionamento positivo entre distribuição de lucros e percentagem de votos dos acionistas minoritários; a evidência encontrada implica, segundo os autores, que quanto mais pulverizada a propriedade da empresa, maior montante de lucro tenderá a ser distribuído.

Grinstein e Michaely (2005) analisaram a presença de investidores institucionais nas empresas norte- -americanas e a distribuição de lucros. Os resultados apontaram para uma associação negativa entre a distribuição de lucros e a presença de investidores institucionais, ou seja, conclui-se que investidores institucionais norte-americanos tendem a preferir investimentos em empresas que prometam ganhos de capital futuros, já que os fluxos de caixa dessa clientela são diferidos para o cumprimento de obrigações atuariais.

Khan (2006) investigou a relação entre a distribuição de lucros e a concentração de propriedade nas empresas do Reino Unido. Os resultados da pesquisa indicaram que concentração de propriedade em poder de grandes grupos empresariais proporciona maior distribuição de dividendos, e concentração de propriedade em poder de acionistas individuais proporciona menor distribuição de dividendos; a interpretação é de que esses investidores aplicam em função de poupanças a serem utilizadas no futuro, enquanto os primeiros têm preferência pela liquidez, em função de sua habilidade em reinvestir valores no mercado financeiro.

Kim, Rhim e Friesner (2007) analisaram se a distribuição de dividendos é influenciada pela concentração de propriedade em empresas da Coreia do Sul. Os resultados indicaram relação positiva entre distribuição de lucros e concentração de propriedade. Dessa forma, pode-se inferir que quão maior for a concentração de propriedade, maior seria a propensão a se apropriar dos fluxos de caixa produzidos pelas firmas amostradas.

Harada e Nguyen (2011) analisaram o relacionamento entre a distribuição de lucros e a concentração de propriedade em empresas do Japão. Nesse caso, a concentração de propriedade foi mensurada pelo índice de Herfindahl, calculado pela soma dos percentuais de ações possuídas pelos cinco maiores acionistas. Já nessa amostra, os achados da pesquisa apontaram relação negativa entre distribuição de lucros e concentração de propriedade, implicando maior controle dos fluxos de caixa produzidos na empresa pelos acionistas controladores.

\section{DESENVOLVIMENTO DA HIPÓTESE}

Analisando as pesquisas realizadas no Brasil sobre o tema, percebe-se que sua atenção esteve voltada para a investigação do impacto marginal da estrutura de propriedade sobre a distribuição de lucros, com ênfase na concentração acionária, preponderantemente presente nas firmas brasileiras. Em tais pesquisas, as 
variáveis representativas da estrutura de propriedade possuíram influência preponderante na menor distribuição de lucros, em função da existência de controladores e mesmo da concentração de propriedade nas empresas brasileiras. Apenas na presença de Conselho de Administração atuante e para ações ordinárias verifica-se o contrário.

Silveira e Bellato (2006), por exemplo, investigaram associação entre o excesso de votos do acionista controlador e a distribuição de lucros nas companhias abertas brasileiras. Os resultados, apesar de estatisticamente não conclusivos, reforçam a ideia de que o incentivo para distribuir lucros é menor em empresas com excesso de votos do controlador, o que indicaria que há benefícios privados auferidos pelos controladores dessas empresas.

Dalmácio e Corrar (2007), por seu lado, investigaram se a composição acionária das empresas negociadas na Bovespa tem relação com a distribuição de lucros por elas adotada. Os autores verificaram que aumento na concentração acionária provoca aumento no valor dos dividendos pagos por ação ordinária; entretanto, existem sinais de que aumento na concentração também provoque uma diminuição na distribuição de lucros para preferencialistas.

Santos (2008) investigou se o perfil dos acionistas controladores pode implicar diferenças na distribuição de lucros. O autor concluiu que quando o acionista controlador faz parte do Conselho de Administração, existe propensão para maior distribuição de lucros; já quando o acionista controlador é entidade governamental, ocorre o contrário. O autor concluiu, ainda, que a concentração de votos, em geral, implica menor distribuição de lucros.

Utilizando o modelo de Elton e Gruber (1970), Procianoy e Verdi (2009) analisaram o Efeito Clientela no mercado brasileiro de ações entre 1996 e 2000 e concluíram que, embora não se possam descartar ajustes advindos do Efeito Clientela nos preços a partir da data ex-dividendo, os resultados do estudo foram contrários às previsões da teoria.

A legislação tributária brasileira privilegia a declaração de dividendos, já que não há tributação nesse ato; já os ganhos de capital são tributados, o que significa diferimento da tributação, além de esta ser acrescida de expectativas futuras já incorporadas ao preço das ações.

À luz da perspectiva da existência do Efeito Clientela, isso significa que entidades com preferência pela liquidez terão reforçados os incentivos para demandar ações de empresas com constantes e altos níveis de payout. Por outro lado, investidores que mantêm investimentos de longo prazo são estimulados a demandar ações de empresas em crescimento e com altas taxas de retenção de lucros, tendo em vista também o diferimento do ato tributário.

O ato tributário em si não demonstrou distinguir classes de clientes influenciando os retornos de ações (PROCIANOY e VERDI, 2009), então se optou por explorar se a especificidade da clientela de determinada firma poderia ter influência na escolha dos gestores em optar por declarar ou não dividendos; mais ainda, se essas peculiaridades, somadas às características de estrutura de propriedade e de governança corporativa, mantêm associação com o nível de payout das firmas brasileiras.

Ampliamos a discussão no sentido de examinar se atributos de acionistas minoritários e características de controle acionário diferenciam as firmas em termos de política de dividendos.

Nossa hipótese é de que segmentos específicos de investidores influenciam a determinação de política de dividendos pelos gestores de firmas no Brasil: há associação estatisticamente significante entre a decisão de declarar dividendos - e seu montante - nas sociedades de capital aberto no Brasil com as características representativas dos grupos de acionistas, da estrutura de propriedade e dos mecanismos de governança corporativa.

\section{DELINEAMENTO DA PESQUISA}

A população-alvo da pesquisa foram as sociedades por ação de capital aberto do Brasil com ações negociadas na BM\&FBovespa no período de 1998 a 2010, com disponibilidade de dados para o processamento dos modelos; esse tipo de firma, por captar recursos em mercado público, pode utilizar a política de dividendos como prática de atração de investidores, no sentido de reduzir seu custo de capital.

Os dados foram coletados na base de dados Economática ${ }^{\circledR}$ e nos Formulários de Referência e de Informações Anuais disponíveis nos sites da BM\&FBovespa e da Comissão de Valores Mobiliários (CVM).

A amostra compreenderia a população de firmas negociadas na BM\&FBovespa; porém, não se consideraram firmas dos setores de seguros e financeiro e também se sacaram observações que impediriam o cálculo de variáveis: 90 empresas/ano apresentando 
payout negativo, em razão de prejuízos reportados, o que afetaria a estimação dos coeficientes; 84 empresas/ ano apresentando maior quantidade de acionistas que de ações - tal informação, sem qualquer fundamento econômico, contábil ou societário, apenas pode ser explicada por incorreção nos dados fornecidos pelas empresas nos documentos entregues à CVM, fonte de nossa coleta - e 257 empresas/ano com informações extremas classificadas como outliers; a identificação e expurgo desses dados obedeceram à técnica da análise do histograma, no qual as observações que não se comportam como as demais da distribuição são consideradas outliers.

A amostra, então, foi composta por 401 firmas, correspondendo a 2.339 empresas/ano. Para efeito de análise, foram seccionadas, ainda, duas subamostras: a primeira contendo as informações pertinentes ao período 1998/2005, associada ao momento econômico da estabilização monetária no Brasil; a segunda considerou as informações no período 2006/2010, admitindo-se que as decisões nesse momento já atendiam a fatores eminentemente mercadológicos e incentivados pela necessidade de captação de recursos.

A variável representativa da Política de Dividendos foi definida como binária, assumindo-se o valor 1 quando tiver havido distribuição de lucro e 0, caso contrário. Em outra formulação, define-se a Política de Dividendos pelo payout do período, utilizando-se a formulação "Dividendos Declarados/Lucro Líquido" de cada ano.

Para a mensuração da distribuição de lucros, não se consideraram valores referentes ao pagamento de juros sobre capital próprio, já que a motivação dos gestores para tanto é eminentemente fiscal, e utilizados pelas firmas que possam ter aproveitamento de vantagens tributárias - foram processadas regressões considerando pagamento de JSCP, as quais não alteram os resultados reportados, o que confirma o caráter fiscal da decisão de pagar JSCP.

Como características representativas da estrutura de propriedade das firmas, que refletem, em última instância, a caracterização dos clientes fornecedores de recursos próprios à firma, estimaram-se as seguintes variáveis: Existência de Acionista Controlador, Percentagem de Votos do Maior Acionista e Disparidade Controle-Propriedade; já como atributos dos acionistas minoritários foram consideradas as variáveis: Total de Acionistas, Presença de Investidores Institucionais, Porcentagem de Ações em Circulação e Existência de Acordo de Acionistas.
Existência de Acionista Controlador assume valor 1 quando um único acionista concentra mais de 50\% das ações ordinárias, sendo-lhe atribuído 0, caso contrário. De acordo com Procianoy (1994), verificou-se que os controladores das empresas brasileiras possuem um forte incentivo para não distribuir a maior parcela possível dos lucros, assim, seguem-se os argumentos do autor, preconizando-se relação negativa com a distribuição de lucros.

Percentagem de Votos do Maior Acionista é calculada pela seguinte fórmula:

$$
P M A=\frac{V}{T}
$$

Em que:

$\mathrm{V}=$ quantidade de ações ordinárias pertencentes ao maior acionista; e

$\mathrm{T}$ = quantidade total de ações ordinárias da empresa

Espera-se que a maior concentração de votos em um único acionista enseje menores níveis de dividendos, já que a satisfação desse acionista poderá estar no uso do benefício privado do controle, ou seja, pela retenção de lucros para financiamento de projetos pessoais do controlador.

A Disparidade Controle-Propriedade está representada pela divergência existente entre o controle e a propriedade da empresa e mede a presença de ações preferenciais na composição do capital da empresa, tendo sido calculada pela relação:

$$
D C P=\frac{Q \cdot A C ̧ \tilde{O E S} \text { ORDINÁRIAS }}{Q \cdot A C ̧ O \tilde{E S S} \text { TOTAIS }}
$$

Essa relação também identifica acionistas cujo maior interesse está no recebimento imediato de sua remuneração, os preferencialistas, os quais não têm maior percepção do futuro da empresa. Por outro lado, alta disparidade de controle-propriedade provoca forte assimetria entre direitos de controle e direitos aos fluxos de caixa gerados; mesmo assim, o proprietário quer garantir os recursos desse tipo, pois não há confronto para suas decisões, o que pode implicar menor propensão para a distribuição de lucro.

O Total de Acionistas representa a quantidade total de acionistas da firma. A variável foi estimada pelo logaritmo da quantidade de acionistas. Firmas com maior pulverização de número de acionistas indicariam ceteris paribus, maior presença de pessoas físicas como 
acionistas, indicando possível interesse em fluxos de caixa regulares, associando tais clientes a propensão à distribuição constante e uniforme de lucros. Desse modo, haveria influência positiva desse Efeito Clientela na taxa de payout.

A Presença de Investidores Institucionais, mensurada por variável binária, que assume valor 1 quando presentes no desenho societário da empresa e 0, caso contrário. Espera-se, por um lado, que maior participação de investidores institucionais aumente a propensão para a distribuição de lucro, se a sua intenção for liquidez para cumprimento de fluxos de caixa passivos, privilegiando o caixa de curto prazo; já noutras ocasiões, esse tipo de acionista pode estar formando reservas para compromissos - atuariais - futuros e, nesse caso, optaria por firmas de maior capitalização com altas taxas de crescimento; embora tais investidores sejam mais eficientes quanto a decisões econômicas, além de poderem exercer, por seu tamanho, influência nos colegiados de decisão da firma, sua associação com níveis de payout fica indefinida.

A Parcela de Ações em Circulação representa a percentagem de ações disponível para negociação no mercado bursátil. A variável foi calculada pela seguinte fórmula:

$$
P A C=\frac{Q \cdot A C \tilde{O} E S \text { NO MERCADO }}{Q \cdot A C \tilde{O} E S \text { TOTAIS }}
$$

Espera-se que maior quantidade de ações nessa categoria enseje maior propensão para a distribuição de lucros, pois, nesse caso, os dividendos teriam conteúdo informacional específico: manter o nível de liquidez da negociação de ações, contribuindo para a redução do custo de capital da firma.

A Existência de Acordo de Acionistas assume valor 1 quando a empresa possui acordo de acionistas e 0 , caso contrário. Espera-se que a Existência de Acordo de Acionistas aumente a propensão para a distribuição de lucro, já que tais acordos permitiriam diluiriam o poder de tomada de decisões na firma, por meio de maior influência colegiada. Contudo, cautela na análise dessa variável deve ser considerada, uma vez que acordos podem significar maior chance de comportamentos oportunistas pelo grupo formado.

Para isolar efeitos que também afetam a propensão a distribuir lucros, foram utilizadas variáveis representativas das seguintes características inerentes às empresas: Tamanho, Oportunidade de Crescimento, Adesão aos Níveis de Governança Corporativa, Geração de Caixa, Rentabilidade do Patrimônio Líquido, Retorno de Mercado, Alavancagem Operacional e Alavancagem Financeira. Ainda se controlaram possíveis impactos macroeconômicos, representados pela variação do PIB e pelo comportamento da taxa básica da economia (Selic). Essas variáveis foram mensuradas conforme fórmulas do Quadro 1.

\section{MODELOS E PROCESSAMENTO}

Inicialmente, investigou-se se há diferenciação estatística na declaração ou não de dividendos; para tan-

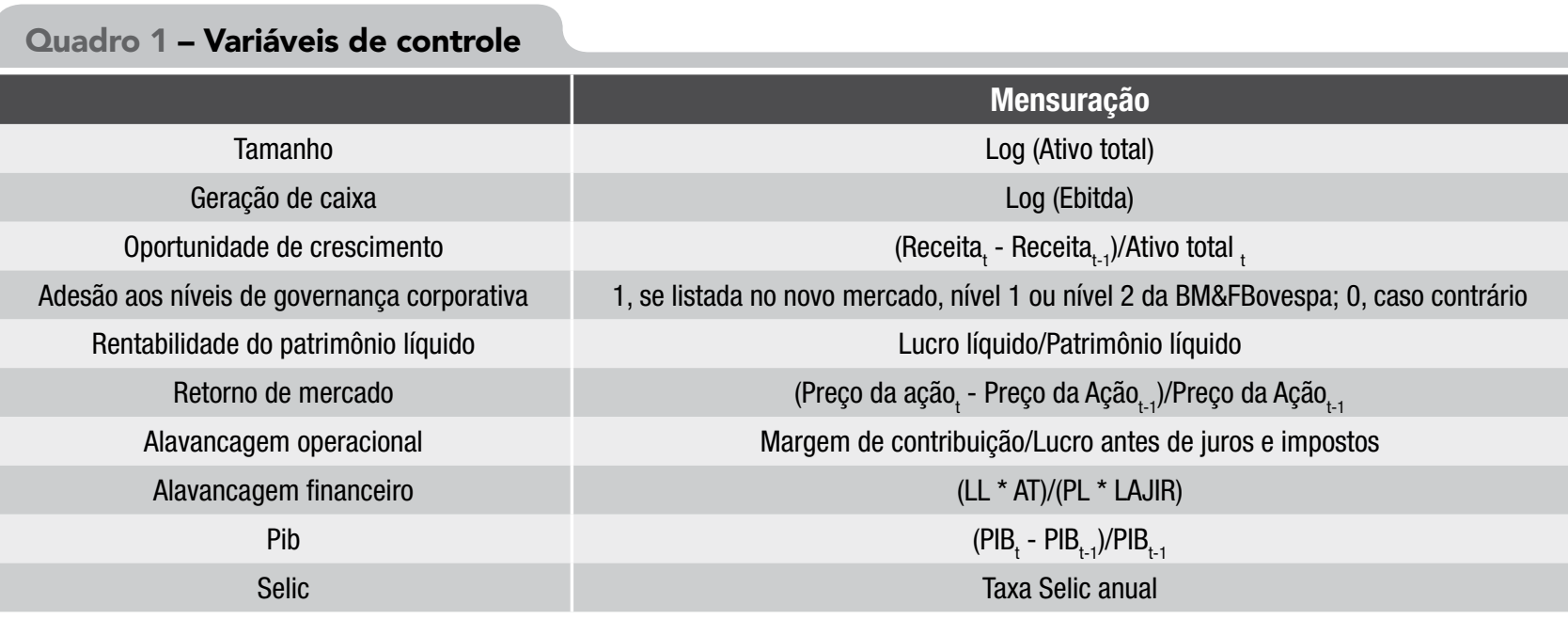


to, utilizou-se regressão logística, segundo o modelo seguinte:

$$
\begin{aligned}
& \log i t\left(D L_{i t}\right)=\beta_{0}+\beta_{1} E A C+\beta_{2} P M A_{i t}+\beta_{3} T A C_{i t}+ \\
& \beta_{4} P I I_{i t}+\beta_{5} D C P_{i t}+\beta_{6} P A C_{i t}+\beta_{7} E A A_{i t}+\beta_{8} T A M_{i t} \\
& +\beta_{9} G E R_{i t}+\beta_{10} O P C_{i t}+\beta_{11} G C_{i t}+\beta_{12} R S P L_{i t}+ \\
& \beta_{13} R E N T_{i t}+\beta_{14} A O_{i t}+\beta_{15} A F_{i t}+\beta_{16} V P I B_{i t}+ \\
& \beta_{17} S_{L L I C}+\varepsilon_{i t}+\varepsilon_{i t}
\end{aligned}
$$

Em que: $D L$ : Distribuição de Lucro; $E A C$ : Existência de Acionista Controlador; PMA: Porcentagem de Ações do Maior Acionista; TAC: Total de acionistas; PII: Presença de Investidores Institucionais; $D C P$ : Disparidade Controle-Propriedade; PAC: Porcentagem de Ações em Circulação; $E A A$ : Existência de Acordo de Acionistas; TAM: Tamanho; GER: Geração de Caixa; OPC: Oportunidade de Crescimento; $G C$ : Adesão aos Níveis de Governança Corporativa; RSPL: Rentabilidade do Patrimônio Líquido; RENT: Retorno de Mercado; $A O$ : Alavancagem Operacional; $A F$ : Alavancagem Financeira; VPIB: Variação do PIB; SELIC: taxa básica da economia; e $\varepsilon$ : Termo de Erro.

A regressão logística (FÁVERO e outros, 2009, p. 440) "destina-se a investigar o efeito das variáveis pelas quais indivíduos, objetos ou sujeitos estão expostos sobre a probabilidade de ocorrência de determinado evento de interesse", ou seja, a técnica destina-se a identificar variáveis que impactam a ocorrência de dado evento, neste estudo, a declaração ou não de dividendos, e possibilitou inferir a intensidade com que as características arroladas segregam sociedades de capital aberto no Brasil, segundo sua opção sobre distribuição de lucros.

Em seguida, investigou-se se nas empresas em que ocorreu distribuição de lucros as variáveis já definidas influenciaram o nível de distribuição de lucros das firmas, estimado pelo payout das firmas. Tal investigação foi realizada por meio de regressão Tobit em duas versões: na primeira, somente se utilizaram variáveis estatisticamente significantes na regressão logística; na segunda, o modelo foi processado de modo integral.

A regressão Tobit estima o relacionamento entre variáveis independentes com dependentes truncadas ou censuradas, ou seja, a técnica busca estimar a influência de variáveis em uma variável dependente, limitadas a um intervalo (RIOS, 2005); neste estudo, buscou-se investigar se características da estrutura de propriedade das firmas brasileiras influência o nível de payout, variável censurada, já que não pode assumir valores menores que zero.
Examinou-se, ainda, se o setor de atuação da empresa continha possíveis elementos de diferenciação no que tange à declaração de dividendos das empresas. Também se controlou as variações temporais comuns a todas as empresas por meio de dummies que representaram os anos da pesquisa.

A análise de correlação entre as variáveis independentes do modelo, não reportada, confirmou ausência de multicolinearidade entre elas, atendendo, portanto, ao pressuposto básico dos métodos Logit e Tobit.

\section{RESULTADOS}

Na Tabela 1, separaram-se os grupos de empresas com e sem distribuição de lucro, com o intuito de examinar se há diferenças significantes entre suas estatísticas descritivas, com base em teste não paramétrico de diferença de médias. Pode-se perceber que apenas as variáveis associadas ao controle das firmas (Existência de Acionista Controlador, Porcentagem de Ações do Maior Acionista, Presença de Investidores Institucionais e Disparidade Controle-Propriedade) demonstraram comportamento similar nos dois grupos, ou seja, o comportamento dos gestores quanto à distribuição de lucros não parece atrelado a atributos que definem o controle acionário das firmas.

Já o nível de circulação de ações é diferenciado estatisticamente nas empresas que declaram e que não declaram dividendos; aquelas com maior parcela de ações em circulação são dominantes em não distribuir dividendos; por outro lado, a quantidade de acionistas e a existência de acordo de acionistas estão associadas positivamente à distribuição de lucros na forma de dividendos.

O nível médio de payout na amostra analisada foi de cerca de $50 \%$ do lucro líquido (30\%, se considerarmos o conjunto total das empresas), indicativo de forte apropriação dos lucros pelos acionistas, não se identificando incentivos ao reinvestimento dos lucros; hipótese razoável para o comportamento repousa na forte presença de financiamento por organismos estatais.

Na Tabela 2, apresentam-se os resultados da regressão logística processada, em que se examinam as características de estrutura de propriedade e atributos de acionistas (Efeito Clientela) que possam diferenciar empresas que distribuíram ou não seus lucros em cada ano da amostra. 
Do ponto de vista da influência dos acionistas na decisão de dividendos, apenas se destacam os atributos referentes à Porcentagem de Ações em Circulação e Disparidade Controle-Propriedade, significantes ao nível de 1\%; as duas estão associadas negativamente à distribuição de lucros; embora esperássemos que a maior parcela de ações em circulação conduzisse à propensão ao pagamento periódico de remuneração a acionistas, a tendência a não distribuir lucros pode estar associada à concentração de ações com investi-

\section{Tabela 1 - Efeito clientela e características das firmas - Estatísticas descritivas}

\begin{tabular}{|c|c|c|c|c|c|c|}
\hline Caracteristica & Dividendos & Média & $\begin{array}{l}\text { Desvio } \\
\text { padrão }\end{array}$ & Mínimo & Máximo & Teste Z \\
\hline \multirow{2}{*}{ Existência de acionista controlador } & Sem & 0,638 & 0,481 & 0,000 & 1,000 & \multirow{2}{*}{$-1,112$} \\
\hline & Com & 0,615 & 0,487 & 0,000 & 1,000 & \\
\hline \multirow{2}{*}{ Porcentagem de ações do maior acionista } & Sem & 45,085 & 24,329 & 5,970 & 100,000 & \multirow{2}{*}{$-1,392$} \\
\hline & Com & 43,919 & 25,055 & 5,270 & 100,000 & \\
\hline \multirow{2}{*}{ Total de acionistas } & Sem & 2,756 & 1,312 & 0,000 & 6,560 & \multirow{2}{*}{$-5,734^{\star * *}$} \\
\hline & Com & 3,035 & 1,376 & 0,000 & 6,522 & \\
\hline \multirow{2}{*}{ Presença de investidores institucionais } & Sem & 0,305 & 0,461 & 0,000 & 1,000 & \multirow{2}{*}{$-0,413$} \\
\hline & Com & 0,297 & 0,457 & 0,000 & 1,000 & \\
\hline \multirow{2}{*}{ Disparidade controle-propriedade } & Sem & 0,600 & 0,260 & 0,002 & 1,060 & \multirow{2}{*}{$-0,706$} \\
\hline & Com & 0,596 & 0,257 & 0,006 & 1,060 & \\
\hline \multirow{2}{*}{ Porcentagem de ações em circulação } & Sem & 34,278 & 39,162 & 0,000 & 100,000 & \multirow{2}{*}{$-2,122^{\star \star}$} \\
\hline & Com & 28,903 & 33,329 & 0,000 & 100,000 & \\
\hline \multirow{2}{*}{ Existência de acordo de acionistas } & Sem & 0,227 & 0,419 & 0,000 & 1,000 & \multirow{2}{*}{$-2,691^{\star \star \star}$} \\
\hline & Com & 0,277 & 0,448 & 0,000 & 1,000 & \\
\hline \multirow{2}{*}{ Tamanho } & Sem & 5,484 & 0,813 & 2,517 & 8,270 & \multirow{2}{*}{$-15,321^{\star \star \star}$} \\
\hline & Com & 6,012 & 0,718 & 3,637 & 8,499 & \\
\hline \multirow{2}{*}{ Geração de caixa } & Sem & $-0,021$ & 0,312 & $-2,685$ & 2,252 & \multirow{2}{*}{$-24,647^{\star \star \star}$} \\
\hline & Com & 0,148 & 0,104 & $-0,098$ & 1,254 & \\
\hline \multirow{2}{*}{ Oportunidade de crescimento } & Sem & 0,005 & 0,280 & $-3,324$ & 1,280 & \multirow{2}{*}{$-9,212^{\star \star \star}$} \\
\hline & Com & 0,079 & 0,190 & $-1,368$ & 1,612 & \\
\hline \multirow{2}{*}{ Adesão aos níveis de governança corporativa } & Sem & 0,144 & 0,352 & 0,000 & 1,000 & \multirow{2}{*}{$-6,016^{\star * *}$} \\
\hline & Com & 0,247 & 0,432 & 0,000 & 1,000 & \\
\hline \multirow{2}{*}{ Rentabilidade do patrimônio líquido } & Sem & $-0,032$ & 0,563 & $-3,160$ & 2,832 & \multirow{2}{*}{$-19,450^{\star * *}$} \\
\hline & Com & 0,172 & 0,166 & 0,001 & 1,918 & \\
\hline \multirow{2}{*}{ Retorno de mercado } & Sem & 18,048 & 73,990 & $-96,700$ & 287,900 & \multirow{2}{*}{$-9,976^{\star \star *}$} \\
\hline & Com & 39,686 & 66,506 & $-91,400$ & 284,900 & \\
\hline \multirow{2}{*}{ Alavancagem operacional } & Sem & 1,329 & 5,938 & $-37,800$ & 39,600 & \multirow{2}{*}{$-8,951^{\star \star *}$} \\
\hline & Com & 1,947 & 4,182 & $-34,000$ & 36,800 & \\
\hline \multirow{2}{*}{ Alavancagem financeira } & Sem & 0,789 & 7,405 & $-39,400$ & 36,800 & $0027 * \star \star$ \\
\hline & Com & 1,565 & 3,039 & $-20,500$ & 39,100 & $-9,83 d^{n n}$ \\
\hline Pavout & Sem & 0,000 & 0,000 & 0,000 & 0,000 & \\
\hline rayout & Com & 0,497 & 0,428 & 0,001 & 3,688 & \\
\hline
\end{tabular}

1) Número de observações: total $=2.339$. Com dividendos $=928$. Sem dividendos $=1.411$.

2) Teste não paramétrico U de Mann-Whitney; ${ }^{\star \star \star}$ Significância estatística ao nível de $1 \%$ e ${ }^{\star \star}$ Significância estatística ao nível de $5 \%$. 
dores institucionais, que influenciariam os gestores a capitalizar os ganhos atuais.

Isso coincide com o comportamento da presença desses investidores, mesmo que apenas na amostra referente ao primeiro período analisado. Também se corrobora tal assertiva pela não significância da variável que expressa a quantidade de acionistas (TAC), indicando a tendência à concentração de propriedade no Brasil (DALMÁCIO e CORRAR, 2007).

Desse modo, esses investidores optariam por ações de maior liquidez, não sendo relevante o recebimento de dividendos, até por conta da facilidade de realizar os investimentos, dada a liquidez do título. Do ponto de vista da empresa, não haveria necessidade da distribuição prioritária de dividendos, embora se garantam menores custos de capital devido à negociabilidade dos títulos.

Pode-se, ainda, inferir que pequenos investidores (pessoa física) não são comuns no mercado brasileiro, predominando investidores institucionais que buscam maximizar retorno em vez de recebimento de renda certa periodicamente.

A relação negativa entre disparidade de controle e propriedade e distribuição de dividendos está associada ao modo legal brasileiro de emissão de preferenciais com características de ordinárias; a maior emissão de preferenciais conduz à distribuição de lucros, seja pelo aspecto compulsório, seja por que esse tipo de ação está associado a investidores que buscam preferencialmente fluxos de caixa temporários, na forma de dividendos.

Outros atributos impactaram marginalmente a propensão para declarar dividendos de maneira significante, quando examinada a amostra referente ao período de estabilização da economia (1998/2005), todos com influência negativa e estatisticamente significantes, quais sejam Participação do Maior Acionista, Presença de Investidores Institucionais, Porcentagem de Ações em Circulação e Existência de Acordo de Acionistas.

Nota-se que o aspecto de concentração de propriedade, seja representado pela alta participação acionária do maior acionista, seja pela conjunção de grandes participações em acordos de acionistas, se constituiu em elemento inibidor de propensão para distribuição de lucros. Uma explicação com base na teoria dos contratos e na teoria da agência seria que os gestores, estando representados pelos próprios acionistas majoritários, não teriam incentivo para remunerar acionistas minoritários, uma vez que pode utilizar-se de mecanismos alternativos de apropriação do fluxo de caixa gerado, tais como altos níveis de remuneração na forma de honorários ou, ainda, pelo uso da estrutura empresarial para sustento de gastos individuais ou por meio de partes relacionadas.

Fato digno de nota é que, na amostra referente ao período 2006/2010, não se identificou atributo significante impactando a propensão para a distribuição de lucro. Mais recentemente, portanto, não se identificam incentivos à distribuição de lucros segundo o Efeito Clientela. Hipótese razoável que explique tal comportamento pode estar relacionada à crise financeira internacional, quando variáveis operacionais ou acauteladoras comandaram as decisões de descapitalização; outra suposição seria de que possíveis distribuições tenham sido feitas de maneira seletiva, via recompra de ações, por exemplo, em face da remessa de reservas pelos investidores estrangeiros.

Vale ressaltar que aparecem como estatisticamente significantes evidências intrínsecas à gestão operacional e financeira da empresa; a aversão ao risco dos gestores na decisão de investimentos impacta a propensão a distribuir lucros, uma vez que tamanho, geração de caixa e retorno (contábil e acionário) são fortemente associados à declaração de dividendos, vale dizer, esse fato está preponderantemente associado à existência de recursos adequados para a decisão de dividendos.

A adesão aos níveis de governança da BM\&FBovespa também contribui para a declaração de dividendos (associação significante e positiva); já empresas alavancadas, tanto operacional como financeiramente, apresentaram relação negativa com a probabilidade de distribuição de lucro; interpretamos tal resultado como sinalização de maior risco dessas empresas, dando relevância à retenção de lucros, mitigando riscos no cumprimento de obrigações fixas das empresas.

Ainda se pode inferir que, nos setores intensivos de capital e em crescimento (Energia Elétrica, Metalurgia, Papel e Celulose, Petroquímica, Transportes, Telecomunicações e Saneamento), as empresas apresentam probabilidade estatisticamente significante de retenção de lucros, já que as componentes de tais setores se caracterizam pela estabilidade de sua atividade ao longo do tempo e pela geração de caixa em curto prazo, propiciando condições para reinvestimento e amortização de financiamentos para investimento.

Prosseguiu-se para examinar se os atributos que possuem impacto marginal na distribuição do lucro também impactam marginalmente no nível de payout, 


\section{Tabela 2 - Propensão para declarar dividendos}

\begin{tabular}{|c|c|c|c|c|}
\hline \multirow[b]{2}{*}{ Variáveis/setores } & \multirow[b]{2}{*}{ Expectativa } & \multicolumn{3}{|c|}{ Coeficiente $\beta$} \\
\hline & & $\begin{array}{l}\text { Amostra } 1 \\
1998-2005\end{array}$ & $\begin{array}{l}\text { Amostra } 2 \\
2006-2010\end{array}$ & $\begin{array}{c}\text { Amostra } \\
\text { total }\end{array}$ \\
\hline Existência de acionista controlador & - & $\begin{array}{c}-0,165 \\
(-0,870)\end{array}$ & $\begin{array}{c}-0,312 \\
(-1,280)\end{array}$ & $\begin{array}{c}-0,211 \\
(-1,500)\end{array}$ \\
\hline Porcentagem de ações do maior acionista & - & $\begin{array}{l}-0,007^{*} \\
(-1,940)\end{array}$ & $\begin{array}{c}0,009 \\
(1,540)\end{array}$ & $\begin{array}{c}-0,002 \\
(-0,580)\end{array}$ \\
\hline Total de acionistas & $?$ & $\begin{array}{c}0,033 \\
(0,650)\end{array}$ & $\begin{array}{c}-0,121 \\
(-1,410)\end{array}$ & $\begin{array}{c}-0,012 \\
(-0,300)\end{array}$ \\
\hline Presença de investidores institucionais & + & $\begin{array}{l}-0,330^{\star *} \\
(-1,960)\end{array}$ & $\begin{array}{c}0,064 \\
(0,340)\end{array}$ & $\begin{array}{c}-0,176 \\
(-1,450)\end{array}$ \\
\hline Disparidade controle-propriedade & - & $\begin{array}{c}-0,371 \\
(-1,120)\end{array}$ & $\begin{array}{c}-0,425 \\
(-1,120)\end{array}$ & $\begin{array}{l}-0,500^{\star *} \\
(-2,120)\end{array}$ \\
\hline Porcentagem de ações em circulação & + & $\begin{array}{l}-0,008^{\star \star \star} \\
(-3,320)\end{array}$ & $\begin{array}{c}-0,004 \\
(-1,190)\end{array}$ & $\begin{array}{l}-0,007^{\star \star \star} \\
(-4,130)\end{array}$ \\
\hline Existência de acordo de acionistas & + & $\begin{array}{l}-0,326^{*} \\
(-1,740)\end{array}$ & $\begin{array}{c}0,027 \\
(0,130)\end{array}$ & $\begin{array}{c}-0,127 \\
(-0,950)\end{array}$ \\
\hline Tamanho & $?$ & $\begin{array}{c}1,176^{\star \star *} \\
(8,560)\end{array}$ & $\begin{array}{c}0,897^{\star \star *} \\
(5,760)\end{array}$ & $\begin{array}{c}0,993^{\star \star *} \\
(9,710)\end{array}$ \\
\hline Geração de caixa & $?$ & $\begin{array}{c}9,498^{\star \star \star} \\
(4,600)\end{array}$ & $\begin{array}{l}5,152^{\star \star} \\
(3,610)\end{array}$ & $\begin{array}{c}7,629 \star \star \star \\
(5,800)\end{array}$ \\
\hline Oportunidade de crescimento & $?$ & $\begin{array}{c}0,424 \\
(0,500)\end{array}$ & $\begin{array}{c}0,373 \\
(1,110)\end{array}$ & $\begin{array}{c}0,502 \\
(1,210)\end{array}$ \\
\hline $\begin{array}{l}\text { Adesão aos níveis de governança } \\
\text { corporativa }\end{array}$ & $?$ & $\begin{array}{l}0,707^{\star} \\
(1,880)\end{array}$ & $\begin{array}{l}0,420^{*} \\
(1,820)\end{array}$ & $\begin{array}{c}0,254 \\
(1,450)\end{array}$ \\
\hline Rentabilidade do patrimônio líquido & $?$ & $\begin{array}{l}1,687^{\star \star \star} \\
(3,450)\end{array}$ & $\begin{array}{c}2,142^{\star \star *} \\
(2,660)\end{array}$ & $\begin{array}{c}1,724^{\star \star \star} \\
(4,250)\end{array}$ \\
\hline Retorno de mercado & $?$ & $\begin{array}{l}0,003^{\star *} \\
(2,260)\end{array}$ & $\begin{array}{c}0,002 \\
(1,130)\end{array}$ & $\begin{array}{c}0,003^{\star \star \star} \\
(3,070)\end{array}$ \\
\hline Alavancagem operacional & $?$ & $\begin{array}{l}0,024^{*} \\
(1,780)\end{array}$ & $\begin{array}{l}-0,018 \\
(-0,910)\end{array}$ & $\begin{array}{c}0,009 \\
(0,840)\end{array}$ \\
\hline Alavancagem financeira & $?$ & $\begin{array}{c}0,023 \\
(1,500)\end{array}$ & $\begin{array}{l}0,035^{\star} \\
(1,740)\end{array}$ & $\begin{array}{l}0,029^{\star *} \\
(2,390)\end{array}$ \\
\hline PIB & $?$ & $\begin{array}{c}0,046 \\
(0,740)\end{array}$ & $\begin{array}{c}0,008 \\
(0,200)\end{array}$ & $\begin{array}{l}0,073^{\star *} \\
(2,460)\end{array}$ \\
\hline Selic & $?$ & $\begin{array}{c}2,325 \\
(0,830)\end{array}$ & $\begin{array}{c}18,643^{\star \star \star} \\
(4,560)\end{array}$ & $\begin{array}{c}6,318^{\star \star \star} \\
(4,810)\end{array}$ \\
\hline Constante & $?$ & $\begin{array}{l}-8,445^{\star \star} \\
(-2,380)\end{array}$ & $\begin{array}{c}-25,580^{\star \star \star} \\
(-5,260)\end{array}$ & $\begin{array}{c}-12,375^{\star \star \star} \\
(-6,860)\end{array}$ \\
\hline $\begin{array}{l}\text { Pseudo } \mathrm{R}^{2} \\
\text { LR chi }{ }^{2} \\
\mathrm{~N}\end{array}$ & & $\begin{array}{c}35,48 \% \\
277,260^{\star \star \star} \\
1495\end{array}$ & $\begin{array}{c}24,86 \% \\
168,600^{\star \star \star} \\
844\end{array}$ & $\begin{array}{c}29,11 \% \\
404,060^{\star \star \star} \\
2339\end{array}$ \\
\hline
\end{tabular}

1) Variável dependente: distribuição de lucros.

2) 0 modelo foi processado com variáveis para os setores, que não estão informados na tabela.

3) Entre parênteses, a Estatística Z.

4) Significância estatística ao nível de $1 \%, 5 \%$ e $10 \%$ é indicada por ${ }^{\star \star \star},{ }^{\star \star} \mathrm{e}^{\star}$, respectivamente. 
dado que evidenciou a probabilidade para declarar dividendos na primeira investigação. Os resultados para esse teste são apresentados na Tabela 3. Aí se constata que:

- As características Participação do Maior Acionista - amostra 1 - e Disparidade Controle-Propriedade - amostra total - apresentaram significância estatística, afetando positivamente o nível de distribuição de dividendo; nesse caso, se indica que, tomada a decisão de distribuir lucro, a concentração de propriedade e de controle funcionam no sentido de incrementar o montante a ser pago aos acionistas;

- De outra parte, a Percentagem de Ações em Circulação - amostra total - impacta negativa e significantemente (embora com coeficiente diminuto) o nível de lucro distribuído; empresas com alta participação de ações no mercado tendem a não distribuir dividendos e, quando o fazem, tendem a utilizar baixas parcelas de payout;

- O montante de dividendo não é afetado pelas demais características dos acionistas definidoras da decisão de declarar dividendos nas empresas pesquisadas;

- Os fatores operacionais, indutores da probabilidade de distribuir lucro, que influenciam, negativamente e com significância, o nível de payout das empresas são a participação em listagens de governança especial da BM\&FBovespa e o retorno sobre patrimônio líquido; já o tamanho da empresa continua significante e impactando positivamente o nível de payout.

Na Tabela 4, são evidenciados os resultados do modelo de regressão estimada via modelo Tobit e processados com todas as variáveis, com a exceção dos setores em que se examina se, no conjunto dos fatores estudados, se identificam associações marginais entre o nível de payout e os fatores representativos do Efeito Clientela.

De um modo geral, se confirmam as inferências já apresentadas nos modelo anteriores, senão vejamos: a) o principal princípio explanatório do montante de payout praticado pelos gestores está marginalmente associados a atributos que revelam a concentração de propriedade predominante nas firmas brasileiras; b) a participação do maior acionista e a disparidade controle-propriedade induzem maiores níveis de payout; contudo, a presença de investidores institucionais e a existência de acionista controlador contrabalançam tal tendência e contribuem para menor distribuição de lucros; c) enfim, a quantidade de acionistas parece estimular os valores de dividendos distribuídos, já que mantêm relação positiva com o nível de payout.

A característica de estrutura de propriedade, isto é, fatores não ligados à eficiência operacional das empresas, que se associou de modo estatisticamente significante com o nível de payout foi a que representa a concentração de propriedade; tal influência é positiva, sugerindo que a propriedade da maior fatia do capital conduz a que se aproprie mais tempestivamente da renda gerada pela empresa. O autofinanciamento do crescimento da empresa não é, aparentemente, prioritário para tal estrutura de propriedade, a não ser na presença de investidores institucionais.

Novamente se evidencia que o tamanho da empresa, mensurado pelo ativo total, influencia positivamente o montante de dividendos declarados.

Numa relação inversa, maiores geração de caixa e rentabilidade do proprietário implicam menor nível relativo de lucro distribuído, como já se apresentava na formulação exposta na Tabela 2. Nesse caso, se evidencia que esse tipo de empresa opta por financiar seu crescimento por meio da retenção de lucros, mesmo que tal retenção aconteça para liquidação de dívidas; apenas teria havido uma antecipação de capital pelos mecanismos de financiamentos por meio de terceiros.

\section{CONCLUSÕES}

O objetivo da pesquisa foi investigar se características externas à operação da empresa e ao seu desempenho de geração de riqueza conseguem diferenciar marginalmente as políticas de dividendos de firmas no ambiente societário brasileiro; os fatores estudados são representativos da estrutura de propriedade, do sistema de governança e do tipo de acionistas, distintivos que se assumiram como proxy para o Efeito Clientela, que pode influenciar a política de dividendos de firmas públicas, segundo a conceituação de teóricos do tema, conforme explicou-se no texto do artigo.

A hipótese de que o mercado de títulos de renda variável onde as empresas brasileiras buscam se financiar se constitui de públicos específicos que demandam ações emitidas por empresas com especificidades em seu desenho institucional pôde ser parcialmente 
confirmada, já que as políticas de distribuição de lucro e a decisão do nível de payout se associam com significância a alguns dos fatores arrolados.

Destaque-se que os atributos que implicam e decorrem da concentração de propriedade no País foram os fatores não econômicos que mais afetaram marginalmente a política de distribuição de lucros das empresas investigadas.

\section{Tabela 3 - Determinantes do nível de payout - Variáveis significantes}

\begin{tabular}{|c|c|c|c|c|}
\hline \multirow[b]{2}{*}{ Variáveis/setores } & \multirow[b]{2}{*}{ Expectativa } & \multicolumn{3}{|c|}{ Coeficiente $\beta$} \\
\hline & & $\begin{array}{l}\text { Amostra } 1 \\
1998-2005\end{array}$ & $\begin{array}{l}\text { Amostra } 2 \\
2006-2010\end{array}$ & $\begin{array}{c}\text { Amostra } 3 \\
\text { total }\end{array}$ \\
\hline Porcentagem de ações do maior acionista & - & $\begin{array}{c}0,002^{\star \star \star} \\
(2,660)\end{array}$ & & \\
\hline Presença de investidores institucionais & + & $\begin{array}{l}-0,004 \\
(-0,130)\end{array}$ & & \\
\hline Disparidade controle-propriedade & - & & & $\begin{array}{c}0,146^{\star \star \star} \\
(3,260)\end{array}$ \\
\hline Porcentagem de ações em circulação & + & $\begin{array}{c}0,001 \\
(1,080)\end{array}$ & & $\begin{array}{l}-0,001^{\star \star} \\
(-1,990)\end{array}$ \\
\hline Existência de acordo de acionistas & + & $\begin{array}{c}0,034 \\
(0,970)\end{array}$ & & \\
\hline Tamanho & $?$ & $\begin{array}{c}0,113^{\star \star \star} \\
(5,340)\end{array}$ & $\begin{array}{c}0,040 \\
(1,530)\end{array}$ & $\begin{array}{c}0,073^{\star \star \star} \\
(4,550)\end{array}$ \\
\hline Geração de caixa & $?$ & $\begin{array}{c}0,035 \\
(0,180)\end{array}$ & $\begin{array}{c}-0,138 \\
(-0,580)\end{array}$ & $\begin{array}{c}0,000 \\
(0,000)\end{array}$ \\
\hline $\begin{array}{l}\text { Adesão aos níveis de governança } \\
\text { corporativa }\end{array}$ & $?$ & $\begin{array}{l}-0,107^{\star *} \\
(-2,140)\end{array}$ & $\begin{array}{l}-0,087^{\star \star} \\
(-2,420)\end{array}$ & \\
\hline Rentabilidade do patrimônio líquido & $?$ & $\begin{array}{l}-0,347^{\star \star} \\
(-2,470)\end{array}$ & $\begin{array}{l}0,286^{\star \star} \\
(2,030)\end{array}$ & $\begin{array}{l}-0,043 \\
(-0,440)\end{array}$ \\
\hline Retorno de mercado & $?$ & $\begin{array}{c}0,000 \\
(0,560)\end{array}$ & & $\begin{array}{c}0,000 \\
(1,020)\end{array}$ \\
\hline Alavancagem operacional & $?$ & $\begin{array}{c}0,005 \\
(1,440)\end{array}$ & & \\
\hline Alavancagem financeira & $?$ & & $\begin{array}{l}-0,004 \\
(-0,730)\end{array}$ & $\begin{array}{l}-0,002 \\
(-0,500)\end{array}$ \\
\hline PIB & $?$ & & & $\begin{array}{l}0,014^{\star \star} \\
(2,290)\end{array}$ \\
\hline Selic & $?$ & & $\begin{array}{l}-1,267 \\
(1,620)\end{array}$ & $\begin{array}{c}0,966^{\star \star \star} \\
(3,530)\end{array}$ \\
\hline Constante & $?$ & $\begin{array}{l}-0,196 \\
(-1,530)\end{array}$ & $\begin{array}{c}-1,202 \\
(-1,330)\end{array}$ & $\begin{array}{c}-1,180^{\star \star \star} \\
(-3,250)\end{array}$ \\
\hline $\begin{array}{l}\text { Pseudo } \mathrm{R}^{2} \\
\text { LR chi }{ }^{2} \\
\mathrm{~N}\end{array}$ & & $\begin{array}{c}4,30 \% \\
48,330^{\star \star \star} \\
919\end{array}$ & $\begin{array}{c}3,87 \% \\
18,030^{\star \star} \\
492\end{array}$ & $\begin{array}{c}2,82 \% \\
45,410^{\star \star \star} \\
1411\end{array}$ \\
\hline
\end{tabular}

1) Variável dependente: payout.

2) Entre parênteses, a Estatística $Z$.

3) Significância estatística ao nível de 1\%,5\% e 10\% é indicada por ${ }^{\star \star \star},{ }^{\star \star} \mathrm{e}^{*}$, respectivamente. 


\section{Tabela 4 - Determinantes do nível de payout - Conjunto de variáveis}

\begin{tabular}{|c|c|c|c|c|}
\hline \multirow[b]{2}{*}{ Variáveis/setores } & \multirow[b]{2}{*}{ Expectativa } & \multicolumn{3}{|c|}{ Coeficiente $\beta$} \\
\hline & & $\begin{array}{l}\text { Amostra } 1 \\
1998-2005\end{array}$ & $\begin{array}{l}\text { Amostra } 2 \\
2006-2010\end{array}$ & $\begin{array}{c}\text { Amostra } 3 \\
\text { total }\end{array}$ \\
\hline Existência de acionista controlador & - & $\begin{array}{c}-0,133^{\star \star \star} \\
(-3,590)\end{array}$ & $\begin{array}{c}-0,036 \\
(-0,730)\end{array}$ & $\begin{array}{l}-0,091^{\star \star *} \\
(-3,060)\end{array}$ \\
\hline Porcentagem de ações do maior acionista & - & $\begin{array}{c}0,003^{\star \star \star} \\
(3,310)\end{array}$ & $\begin{array}{c}0,003^{\star * *} \\
(2,830)\end{array}$ & $\begin{array}{c}0,003^{\star \star \star} \\
(4,140)\end{array}$ \\
\hline Total de acionistas & $?$ & $\begin{array}{c}-0,003 \\
(-0,300)\end{array}$ & $\begin{array}{c}0,038^{\star \star \star} \\
(2,480)\end{array}$ & $\begin{array}{c}0,011 \\
(1,200)\end{array}$ \\
\hline Presença de investidores institucionais & + & $\begin{array}{c}-0,017 \\
(-0,500)\end{array}$ & $\begin{array}{c}-0,114^{\star \star *} \\
(-3,110)\end{array}$ & $\begin{array}{l}-0,054^{\star \star} \\
(-2,110)\end{array}$ \\
\hline Disparidade controle-propriedade & - & $\begin{array}{l}0,173^{\star \star} \\
(2,550)\end{array}$ & $\begin{array}{c}0,061 \\
(0,900)\end{array}$ & $\begin{array}{l}0,108^{\star *} \\
(2,240)\end{array}$ \\
\hline Porcentagem de ações em circulação & + & $\begin{array}{l}0,001^{*} \\
(1,670)\end{array}$ & $\begin{array}{c}0,000 \\
(0,400)\end{array}$ & $\begin{array}{c}0,000 \\
(0,370)\end{array}$ \\
\hline Existência de acordo de acionistas & + & $\begin{array}{c}0,007 \\
(0,200)\end{array}$ & $\begin{array}{c}0,051 \\
(1,330)\end{array}$ & $\begin{array}{c}0,039 \\
(1,450)\end{array}$ \\
\hline Tamanho & $?$ & $\begin{array}{c}0,119^{\star \star *} \\
(5,140)\end{array}$ & $\begin{array}{c}0,005 \\
(0,160)\end{array}$ & $\begin{array}{c}0,079^{\star \star \star} \\
(4,360)\end{array}$ \\
\hline Geração de caixa & $?$ & $\begin{array}{c}-0,021 \\
(-0,110)\end{array}$ & $\begin{array}{c}-0,274 \\
(-1,160)\end{array}$ & $\begin{array}{c}-0,041 \\
(-0,280)\end{array}$ \\
\hline Oportunidade de crescimento & $?$ & $\begin{array}{c}-0,016 \\
(-0,220)\end{array}$ & $\begin{array}{c}-0,150 \\
(-1,430)\end{array}$ & $\begin{array}{l}-0,054 \\
(-0,880)\end{array}$ \\
\hline $\begin{array}{l}\text { Adesão aos níveis de governança } \\
\text { corporativa }\end{array}$ & $?$ & $\begin{array}{l}-0,085^{\star} \\
(-1,690)\end{array}$ & $\begin{array}{l}-0,037 \\
(-0,860)\end{array}$ & $\begin{array}{l}-0,099^{\star \star \star} \\
(-3,070)\end{array}$ \\
\hline Rentabilidade do patrimônio líquido & $?$ & $\begin{array}{l}-0,343^{*} \\
(-2,410)\end{array}$ & $\begin{array}{l}0,285^{\star \star} \\
(2,060)\end{array}$ & $\begin{array}{l}-0,048 \\
(-0,490)\end{array}$ \\
\hline Retorno de mercado & $?$ & $\begin{array}{c}0,000 \\
(0,510)\end{array}$ & $\begin{array}{l}0,001^{\star \star} \\
(2,290)\end{array}$ & $\begin{array}{c}0,000 \\
(1,060)\end{array}$ \\
\hline Alavancagem operacional & $?$ & $\begin{array}{c}0,004 \\
(1,210)\end{array}$ & $\begin{array}{c}0,002 \\
(0,340)\end{array}$ & $\begin{array}{c}0,004 \\
(1,510)\end{array}$ \\
\hline Alavancagem financeira & $?$ & $\begin{array}{l}-0,001 \\
(-0,220)\end{array}$ & $\begin{array}{l}-0,004 \\
(-0,660)\end{array}$ & $\begin{array}{l}-0,001 \\
(-0,360)\end{array}$ \\
\hline PIB & $?$ & $\begin{array}{l}-0,013 \\
(-0,950)\end{array}$ & $\begin{array}{c}0,022^{\star \star \star} \\
(2,830)\end{array}$ & $\begin{array}{l}0,013^{\star \star} \\
(2,140)\end{array}$ \\
\hline Selic & $?$ & $\begin{array}{l}-0,695 \\
(-1,120)\end{array}$ & $\begin{array}{l}1,487^{\star} \\
(1,880)\end{array}$ & $\begin{array}{c}0,789 * * * \\
(2,830)\end{array}$ \\
\hline Constante & $?$ & $\begin{array}{c}0,613 \\
(0,790)\end{array}$ & $\begin{array}{l}-1,603^{*} \\
(-1,750)\end{array}$ & $\begin{array}{c}-1,069^{\star \star \star} \\
(-2,930)\end{array}$ \\
\hline $\begin{array}{l}\text { Pseudo R2 } \\
\text { LR chi }{ }^{2} \\
\text { N }\end{array}$ & & $\begin{array}{c}6,59 \% \\
74,170^{\star \star \star} \\
919\end{array}$ & $\begin{array}{c}12,59 \% \\
58,690^{\star \star \star} \\
492\end{array}$ & $\begin{array}{c}5,61 \% \\
90,330^{\star * *} \\
1411\end{array}$ \\
\hline
\end{tabular}


Os achados confirmaram também que tanto a decisão de declarar dividendos quanto o seu montante foram afetados por variáveis operacionais, no caso, geração de caixa, rentabilidade do patrimônio líquido, retorno de mercado e tamanho do ativo, além de adesão a níveis de governança corporativa.

Todavia, não se identificaram razões atreladas à necessidade de financiamento ou aos esquemas conceituais de distribuição de lucros associada aos planos de financiamento de novos investimentos, uma vez que os coeficientes referentes a alavancagem financeira e oportunidades de crescimento demonstraram-se sem significância tanto para indicar a declaração dos dividendos quanto para definir o montante distribuído.

Por fim, para pesquisas futuras, pode-se sugerir a inclusão de outras características representativas da estrutura de propriedade, bem como destacar a predominância do tipo de financiamento com capital de terceiros das firmas, buscando alcançar resultados mais conclusivos sobre o tema. Sugere-se, ainda, o uso de outros métodos, como a Análise Discriminante, para complementar a Regressão Logística.

\section{REFERÊNCIAS}

BLACK, F. The dividend puzzle. The Journal of Portfolio Management, Special Issue, p. 1-12, 1996.

BRASIL. Lei no 6.404, de 15.12.1976. Dispõe sobre as sociedades por ações. Diário Oficial [da] República Federativa do Brasil, Poder Executivo, Brasília, DF, 17.12.1976.

BUENO, A. F. Análise empirica do dividend yield das ações brasileiras. 2000. 202 p. Dissertação de Mestrado em Controladoria e Contabilidade, Faculdade de Economia, Administração e Contabilidade da Universidade de São Paulo, São Paulo, 2000.

COELHO, A. C. D. Qualidade informacional e conservadorismo nos resultados contábeis publicados no Brasil. 2007. 240 p. Tese de Doutorado em Contabilidade e Controladoria, Faculdade de Economia, Administração e Contabilidade da Universidade de São Paulo, São Paulo, 2007.

DALMÁCIO, F. Z; CORRAR, L. J. A concentração do controle acionário e a política de dividendos das empresas listadas na Bovespa: uma abordagem exploratória à luz da teoria de agência. Revista de Contabilidade e Organizações, v. 1, n. 1, p. 16-29, 2007.

ELTON, E. J; GRUBER, M. J. Marginal stockholders tax rates and the clientele effect. Review of Economics and Statistics, v. 52, n. 1, p. 68-74, 1970.

FÁVERO, L. P. e outros. Análise de dados: modelagem multivariada para a tomada de decisões. Rio de Janeiro: Campus, 2009.

GORDON, M. J. Dividends, earning, and stock prices. Review of Economics and Statistics, v. 41, n. 2, p. 99-105, 1959.

GRAHAM, J. R; KUMAR, A. Do dividend clienteles exist? Evidence on dividend preferences of retail investors. The Journal of Finance, v. 61, n. 3, p. 1305-1336, 2006.

GRINSTEIN, Y; MICHAELY, R. Institutional holdings and payout policy. The Journal of Finance, v. 60, n. 3, p. 13891426, 2005.

HARADA, K; NGUYEN, P. Ownership concentration and dividend policy in Japan. Managerial Finance, v. 37, n. 4, p. 362-379, 2011.

JENSEN, M. C.; MECKLING, W. H. Theory of the firm: managerial behavior, agency costs of and ownership structure. Journal of Financial Economics, v. 3, n. 4, p. 305-360, 1976.

KHAN, T. Company dividends and ownership structure: evidence from UK panel data. The Economic Journal, v. 116, n. 510, p. C172-C189, 2006.

KIM, Y. H; RHIM, J. C; FRIESNER, D. L. Interrelationships among capital structure, dividends, and ownership: evidence from South Korea. The Multinational Business Review, v. 15, n. 3, p. 25-42, 2007.

LA PORTA, R. e outros. Agency problems and dividend policies around the world. The Journal of Finance, v. 55, n. 1, p. 1-33, 2000.

LINTNER, J. Distribution of incomes of corporations among dividends, retained earnings, and taxes. American Economic Review, v. 46, n. 2, p. 97-113, 1956.

LOSS, L; SARLO NETO, A. Política de dividendos, na prática, é importante? Revista de Contabilidade e Finanças, Edição Comemorativa, p. 39-53, 2003. 
MILLER, M. H; MODIGLIANI, F. Dividend policy, growth and the valuation of shares. Journal of Business, v. 34, n. 4, p. 411-433, 1961.

PROCIANOY, J. L. Conflitos de agência entre controladores e minoritários nas empresas brasileiras negociadas na bolsa de valores de São Paulo: evidências através do comportamento da política de dividendos após as modificações tributárias ocorridas entre 1988-1989. 1994. 74 p. Tese de Doutorado em Contabilidade e Controladoria, Faculdade de Economia, Administração e Contabilidade da Universidade de São Paulo, São Paulo, 1994.

PROCIANOY, J. L; VERDI, R. S. O efeito clientela no mercado brasileiro: será que os investidores são irracionais? Revista Brasileira de Finanças, v. 1, n. 2, p. 217-242, 2003.

PROCIANOY, J. L; VERDI, R. S. Dividend clientele, new insights, and new questions: the Brazilian case. RAE-eletrônica, v. 8, n. 1, 2009. Disponível em http://rae.fgv.br/ rae-eletronica/vol8-num1-2009/dividend-clientele-new-insights-and-new-questions-brazilian-case. Acesso em 03.05.2012.

RIOS, L. R. Medindo a eficiência relativa das operações dos terminais de contêineres do MERCOSUL. 2005. 148 p. Dissertação de Mestrado em Administração, Escola de Administração da Universidade Federal do Rio Grande do Sul, Porto Alegre, 2005.

ROSS, S. The determinantion of financial structure: the incentive-signalling approach. The Bell Journal of Economics, v. 8, n. 1, p. 23-40, 1977.

SANTOS, R. F. C. Perfil dos acionistas controladores das empresas brasileiras e suas implicações para a política de dividendos. 2008. 117 p. Dissertação de Mestrado em Economia Aplicada, Faculdade de Economia, Administração e Contabilidade da Universidade de São Paulo, São Paulo, 2008.

SILVEIRA, A. D. M; BELLATO, L. L. N. Influência da estrutura de propriedade sobre a política de dividendos das companhias abertas brasileiras. In: ENCONTRO BRASILEIRO DE FINANÇAS, 6, 2006, Vitória. Anais. Vitória: SBFIN, 2006.

VERDI, R. S. A influência dos impostos sobre o pagamento de dividendos no preço das ações: um estudo do mercado brasileiro. 2001. 81 p. Dissertação de Mestrado em Administração, Programa de Pós-Graduação em Administração da Universidade Federal do Rio Grande do Sul, Porto Alegre, 2001. 